Research Article

\title{
Transition in pharmacology: From theoretical knowledge of medicines to practice-oriented approach. Do role-plays help?
}

\author{
Lavanya SH*, Kalpana L, Veena RM, Bharath Kumar VD
}

Department of Pharmacology, BGS Global Institute of Medical Sciences, Bangalore, Karnataka, India

Received: 27 May 2016

Accepted: 01 July 2016

\section{*Correspondence to:}

Dr. Lavanya SH,

Email: lavanyasumanthraj@ gmail.com

Copyright: (C) the author(s), publisher and licensee Medip Academy. This is an openaccess article distributed under the terms of the Creative Commons Attribution NonCommercial License, which permits unrestricted noncommercial use, distribution, and reproduction in any medium, provided the original work is properly cited.

\begin{abstract}
Background: Pharmacology, a subject criticized by medicos as 'dry and volatile' is in a stage of constant reformation. Traditional teaching-learning in pharmacology has focused more on theoretical knowledge of medicines with little emphasis on the art and science of communicating the same to patients in actual practice. Role-play is one novel method which attracts learners to gain knowledge through concrete experience, there-by bringing in a behavioural change that persists eventually. The objective of this study was to evaluate the effectiveness of role-play as an educational tool in teaching patient education and counseling skills regarding medications prescription for ischemic heart disease (IHD).

Methods: A quantitative, randomized, interventional study with pre \& postOSPE using a pre-validated checklist (modified-Calgary-Cambridge) was conducted in 84, II-MBBS students. The scores obtained in intervention group (Lecture-IHD counseling + Role-play) were compared with the control group (Lecture) using Wilcoxon test for paired-data and Mann-Whitney test for intergroup comparisons.

Results: Paired-data analysis showed an increase in post-test mean scores in both control and intervention groups following training. However, inter-group comparisons revealed statistically significant improvement in 8 of the 13 parameters in intervention group. Students in intervention group stressed more on pharmacological aspects of medications, along with emergency measures and need for follow-up. Hence it can be said that role-plays played a significant role in improving communication skills regarding medications prescription.

Conclusions: Medical communication skills course for II-MBBS students may enable them to demonstrate better patient-doctor interactions. Role-plays are an effective tool to acquire technical and behavioural skills to deal with real-life situations through simulation.
\end{abstract}

Keywords: Communication skills, Prescription, Pharmacology, Role-play, Teaching tool

\section{INTRODUCTION}

Acquiring adequate knowledge about drugs and its rational application in clinical practice is considered to be one of the preliminary steps in preparing undergraduate medical students for future practice. ${ }^{1}$ In this era of knowledge explosion, students often face difficulty in remembering details especially in context to the subject of pharmacology. Though pharmacology forms the backbone of rational therapeutics, unfortunately this subject also bears the academic stigma of being one of the driest and boring subjects. A major attribute to this fact happens to be the traditional way of teaching and learning which focuses more on imparting theoretical knowledge of medicines rather than on using them in actual clinical practice. ${ }^{2,3}$ So, how do we re-shape our students' attitude towards pharmacology and make them study this subject mindfully and not just mechanically?

The answer to this question would be to adopt innovative teaching techniques that promote critical reflective thinking and integration into system-based, organ-based and clinical presentation-based curriculum. This way, students will be challenged to apply these principles to 
the understanding of therapeutic agents that they will come across subsequently in clinical encounters. ${ }^{4}$ Fortunately, numerous attempts have been made by subject experts in trying out novel teaching-learning methodologies to rekindle the enthusiasm of students towards the subject, which in turn may steer them to learn the various technical and behavioural skills in a holistic manner. ${ }^{5}$

Role-play is one such method which attracts the learner to gain knowledge and experience to deal with real-life situations through simulation, so that they can apply the same in clinical practice. ${ }^{6}$ This way, role-plays bring in a behavioural change that persists over time. ${ }^{6}$ Numerous studies have highlighted the effectiveness of role-play in helping students develop communication skills in clinical medicine. ${ }^{6,7}$ However, there are only a few studies about role-plays in the pharmacology segment and to the best of the authors' knowledge, not many studies have evaluated its usefulness as a teaching-learning tool in patient education and counseling skills regarding medications prescription.

The objective of this study was to evaluate the effectiveness of role-play as an educational tool in teaching patient education and counseling skills regarding prescription of medications for ischemic heart disease (IHD).

\section{METHODS}

This quantitative, interventional study was conducted in the Department of Pharmacology, BGS Global Institute of Medical Sciences, Bangalore, Karnataka India. Approval was obtained by the institutional ethics committee for the conduct of study. Second MBBS students $(n=88)$ attending pharmacology classes were invited to be a part of the study. Students were duly informed that their participation was purely voluntary and a written informed consent was taken from the willing students. The students were randomized to two groups, control and intervention group $(n=44)$ each. A prevalidated checklist based on the modified CalgaryCambridge guide item with specific emphasis on explanation and planning was used to evaluate the effectiveness of role-play.

\section{Methodology}

Students in both the groups attended a pharmacology lecture class on anti-anginal drugs. This was followed by a pre-OSPE (Objective-Structured Practical Examination) exercise to obtain the baseline prescription counseling skills of these students in a case of IHD. All students then attended a lecture class on general aspects of communication skills (both verbal and non-verbal), along with the technical aspects of IHD medication counseling (problem-oriented learning). The students in the control group were then evaluated with a post-OSPE.
The counseling skills were taught during a separate practical session by means of a peer role-play technique to the intervention group. The teacher gave a theoretical presentation of the role-play procedure and rules for giving feedback. The students in groups of three (2actors; 1-observer), performed role play using the prepared case-scenario. At the end of each session, feedback was obtained from the observer and the remaining student audiences. The teacher moderated the sessions. This was followed by a post-OSPE session. Both the pre and post-OSPE examination was conducted by the same set of examiners and the scores obtained were recorded and analysis of data was done using Wilcoxon test for paired-data and Mann-Whitney test for inter-group comparisons.

\section{RESULTS}

A total of $84(95.5 \%)$ students completed the study. Data was entered into datasheet after coding and was analysed by using SPSS version 22 software. Wilcoxon signed rank test was used as test of significance for paired data i.e. to compare intra-group mean pre-test and post-test score. Mann-Whitney $U$ test was used as test of significance to identify the mean difference between the two groups. $\mathrm{P}$ value $<0.05$ was considered as statistically significant.

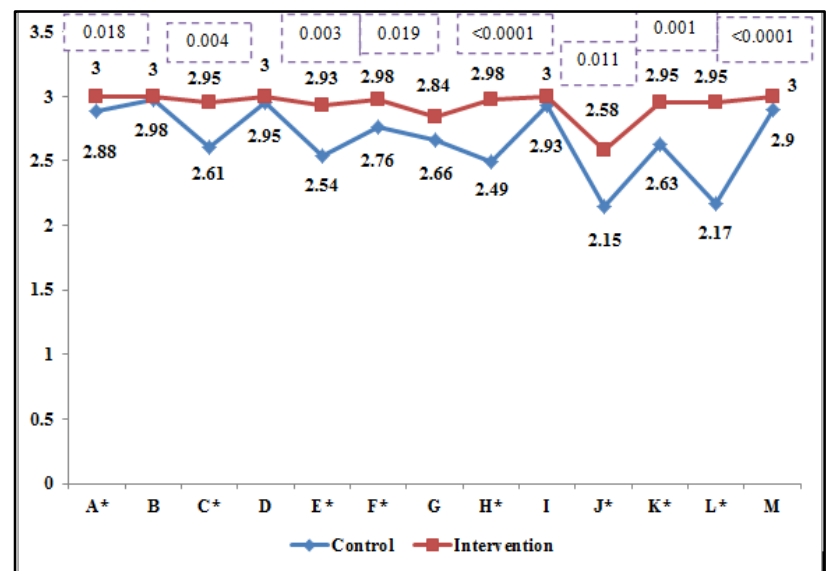

*Parameters that demonstrated significant improvement in the intervention group; A: Introduces self to patient and informs of intent of consultation; B: Mentions drug name; C: Explains how drugs work; D: Dose and Duration of therapy; E: Benefits of therapy; F: Possible side effects; G: Need for compliance; H: Explains warning signs and measures to be taken during acute attack; I: Life-style modifications; J: Checks patient agreement with treatment; K: Encourages questions; L: Discusses followup; M: Ends conversation politely.

\section{Figure 1: Mean post-test scores comparison between study groups.}

In the study majority of subjects were females $59(70.2 \%)$ and $25(29.8 \%)$ were males. There was no significant gender difference between control and intervention groups. The mean pre-test scores for all parameters were identical, with no significant difference between the groups. A significant improvement in the post-test scores 
was noted in both the study groups. However, scores of 3 were commonly seen in the intervention group (Table 1).

Inter-group mean post-test scores comparison revealed a statistically significant improvement in 8 of the 13 parameters in the intervention group. Students in the intervention group stressed more on the pharmacological aspects of medications, the measures to be taken during an emergency and the importance of medication compliance and follow-up (Figure 1).

Table 1: Pre-test and post-test mean scores comparison in control and intervention groups.

\begin{tabular}{|c|c|c|c|c|c|c|}
\hline \multirow[b]{2}{*}{ Parameters } & \multicolumn{3}{|c|}{ Control group (n=41) } & \multicolumn{3}{|c|}{ Intervention group $(\mathrm{n}=\mathbf{4 3})$} \\
\hline & $\begin{array}{l}\text { Pre test } \\
\text { mean score }\end{array}$ & $\begin{array}{l}\text { Post test } \\
\text { mean score }\end{array}$ & $p$ value & $\begin{array}{l}\text { Pre test } \\
\text { mean score }\end{array}$ & $\begin{array}{l}\text { Post test } \\
\text { mean score }\end{array}$ & p value \\
\hline $\begin{array}{l}\text { A = Introduces self to patient } \\
\text { and informs of intent of } \\
\text { consultation }\end{array}$ & 2.44 & 2.88 & $<0.0001 *$ & 2.26 & 3.00 & $<0.0001 *$ \\
\hline $\mathbf{B}=$ Mentions drug name & 2.88 & 2.98 & 0.210 & 2.58 & 3.00 & $0.0028 *$ \\
\hline $\mathbf{C}=$ Explains how drugs work & 1.51 & 2.61 & $<0.0001^{*}$ & 1.30 & 2.95 & $<0.0001^{*}$ \\
\hline $\begin{array}{l}\mathbf{D}=\text { Dose and duration of } \\
\text { therapy }\end{array}$ & 2.44 & 2.95 & $0.001^{*}$ & 2.65 & 3.00 & $0.004 *$ \\
\hline $\mathbf{E}=$ Benefits of therapy & 1.24 & 2.54 & $<0.0001 *$ & 1.30 & 2.93 & $<0.0001 *$ \\
\hline $\mathbf{F}=$ Possible side effects & 1.95 & 2.76 & $<0.0001^{*}$ & 1.77 & 2.98 & $<0.0001 *$ \\
\hline $\mathbf{G}=$ Need for compliance & 1.46 & 2.66 & $<0.0001^{*}$ & 1.49 & 2.84 & $<0.0001 *$ \\
\hline $\begin{array}{l}\mathbf{H}=\text { Explains warning signs } \\
\text { and measures to be taken } \\
\text { during acute attack }\end{array}$ & 1.20 & 2.49 & $<0.0001 *$ & 1.26 & 2.98 & $<0.0001 *$ \\
\hline $\mathbf{I}=$ Life-style modifications & 2.59 & 2.93 & $0.003^{*}$ & 2.37 & 3.00 & $<0.0001^{*}$ \\
\hline $\begin{array}{l}\mathbf{J}=\text { Checks patient agreement } \\
\text { with treatment }\end{array}$ & 1.44 & 2.15 & $<0.0001^{*}$ & 1.40 & 2.58 & $<0.0001^{*}$ \\
\hline $\mathbf{K}=$ Encourages questions & 1.95 & 2.63 & $<0.0001^{*}$ & 1.65 & 2.95 & $<0.0001 *$ \\
\hline $\mathbf{L}=$ Discusses follow-up & 1.61 & 2.17 & $<0.0001 *$ & 1.70 & 2.95 & $<0.0001^{*}$ \\
\hline $\begin{array}{l}\text { M = Ends conversation } \\
\text { politely }\end{array}$ & 2.34 & 2.90 & $<0.0001^{*}$ & 2.37 & 3.00 & $<0.0001 *$ \\
\hline
\end{tabular}

*P value <0.05 considered statistically significant; \# Adapted and modified from Kurtz SM, Silverman JD, Draper J (1998) teaching and learning communication. Skills in Medicine. Radcliffe medical press (Oxford); Silverman JD, Kurtz SM, Draper J (1998) Skills for communicating with patients. Radcliffe medical press (Oxford). ${ }^{8,9}$

\section{DISCUSSION}

Medical education in India is in a stage of constant reformation and pharmacology too is not left behind in adopting novel teaching techniques. Numerous studies conducted in medical students have demonstrated the effectiveness of role-play in teaching technical and communication skills in medical education..$^{6,70,11}$ In our study, we used the peer-role play technique that involved all the students to perform, learn and to personally experience patient concerns in front of their peers. Continuous feedback from peers gave the students an opportunity to sharpen their communication skills in a safe and supportive classroom environment. ${ }^{12,13}$

It is evident from our study findings that students in both groups showed significant improvement in post-test scores for almost all the parameters. This was a welcome finding which re-iterated our belief that it is vital to instil in our students, all important skills needed by a medical graduate in today's world especially in context to pharmacology. However, an inter-group comparison revealed that the students in the role-play group demonstrated better scores, with a statistically significant improvement in 8 of the 13 study parameters. These parameters reflected the students' improved ability in remembering, recollecting and synthesizing pharmacological facts and its application in real-life situations (higher cognitive domain) and also their improved behaviour and communication towards patients (affective domain) after being sensitized to role-plays. These findings are similar to the results of the study conducted by Acharya S et al. ${ }^{6}$

Given the magnitude of the IHD problem and the need for prompt treatment, the medical management of IHD is a must know topic in pharmacology. As per the Knowles' principles of adult learning, students learn best when they are involved in the subject matter, when they have a need to know or when there is an internal motivation to learn. Through role-plays which are based on problem-oriented 
clinical scenarios, the students see themselves in the clinical situation, observe, reflect and in the process, they holistically learn the nuances of theoretical, practical, clinical and behavioural aspects of clinical problem solving. ${ }^{6,14}$ It has been proposed that students learn in different ways and role-plays are beneficial in individuals who learn through concrete experience. Hence it may not be reasonable to totally attribute the improvement in scores to a singular educational method. Despite this, role-plays could still be considered a valuable additional tool in promoting learning through thinking, feeling, watching and doing. ${ }^{6}$

The application of the principles of pharmacology becomes the foundation for therapeutics. It is the need of the hour to emphasize that foundational concepts are important for clinical decision making. ${ }^{4}$ Role-plays may play a substantial part in bridging the transfer of knowledge about drugs to treating patients in a given situation.

The main limitation of the study was that it used a single case-scenario of IHD. Additional studies involving multiple clinical scenarios might increase our understanding of the usefulness of role-plays in optimizing transfer (i.e improving students' ability to use a concept learned in one context to solve a problem in a different context). This study was conducted in a controlled and supportive classroom setting, which evokes a sense of comfort within the learners. It would be interesting to see how much of this increased knowledge or behaviour change actually translates to clinical efficiency in the real-life scenario.

\section{CONCLUSION}

Pharmacology is a unique foundational discipline whose clinical relevance carries over into the clinical years and far way beyond. Teaching the integration of theoretical aspects of pharmacology into clinical practice is definitely a daunting task. Such transitions are challenging and will require motivated academic pharmacologists to adopt interesting and relevant teaching methods. A course on medical communication skills may enable medical students to demonstrate better interaction proficiencies. Role-plays are a valuable additional tool to acquire knowledge, attitudes and skills in a range of disciplines. By fostering concrete experience and reflective thinking, role-plays bring in a behavioural change that encourages students to apply knowledge to practice. It's time we seriously consider inculcating role-plays as an educational tool in the current system of pharmacology teaching.

\section{ACKNOWLEDGEMENTS}

The authors would like to sincerely thank the management, principal, faculty and students of BGSGIMS for their unconditional support throughout the study process. Our sincere thanks to statistician Dr. Mahesh for his timely inputs. A special thanks to St.
John's Medical College MEU team and the FIME 2015 a batch for their constant encouragement.

Funding: No funding sources

Conflict of interest: None declared

Ethical approval: The study was approved by the Institutional Ethics Committee

\section{REFERENCES}

1. Kamath A. A review of use of e-learning in pharmacology. Int J Intg Med Sci. 2015;2(9):157-62.

2. Joshi A, Trivedi M. Innovations in pharmacology teaching. Int $\mathrm{J}$ Pharmaceut Biomed Res. 2010;1(2):62-4.

3. Bhosale UA, Yegnanarayan R, Yadav GE. Attitude, perception and feedback of second year medical students on teaching-learning methodology and evaluation methods in pharmacology: A questionnaire-based study. Niger Med J. 2013;54(1):33-9.

4. Jefferies WB, McMahon KK, Rosenfeld GC, Strandhoy JW, Szarek J, Wilson-Delfosse A. Pharmacology-in the face of revisiting flexner's view of medical education. JIAMSE (Medical Science Educator). 2010;20(3):288-92.

5. Garg PV, Muchandi RK. Students' opinion on the prevailing teaching methods in pharmacology and changes recommended. Indian $\mathbf{J}$ Pharmacol. 2004;36(3);155-8.

6. Acharya S, Shukla S, Acharya N, Vagha J. Role playan effective tool to teach clinical medicine. J Contemp Med Edu. 2014;2(2);91-6.

7. Nestel D, Tierney T. Role-play for medical students learning about communication: guidelines for maximising benefits. BMC Med Educ. 2007;7:3.

8. Kurtz SM, Silverman JD, Draper J. Teaching and learning communication. Skills in Medicine. Radcliffe Medical Press (Oxford); 1998. Available at http://www.gptraining.net/training/communication_skills/calgary/.

9. Silverman JD, Kurtz SM, Draper J. Skills for Communicating with Patients. Radcliffe Medical Press (Oxford); 1998. Available at http://www.gptraining.net/training/communication_skills/calgary/.

10. Luttenberger K, Graessel E, Simon C, Donath C. From board to bedside-training the communication competences of medical students with role plays. BMC Med Educ. 2014;14:135.

11. Nikendei C, Kraus B, Schrauth M, Weyrich P, Zipfel $\mathrm{S}$, Herzog $\mathrm{W}$, et al. Integration of role-playing into technical skills training: a randomized controlled trial. Med Teach. 2007;29(9):956-60.

12. Luiz Adrian JA, Zeszotarski P, Ma C. Developing pharmacy student communication skills through roleplay and active learning. Am $\mathbf{J}$ Pharm Educ. 2015;79(3):44.

13. Bosse HM, Nickel M, Huwendiek S, Jünger J, Schultz JH, Nikendei C. Peer role-play and standardised patients in communication training: a 
comparative study on the student perspective on acceptability, realism, and perceived effect. BMC Med Educ. 2010;10:27.

14. Knowles MS, Holton EF, Swanson RA. The adult learner: the definitive classic in adult education and human resource development. $6^{\text {th }}$ ed. USA: Elsevier; 2005. Available at file:///C:/Users/india/Downloads/the_adult_learner\% 20a4-2.pdf.

Cite this article as: Lavanya SH, Kalpana L, Veena RM, Bharath Kumar VD. Transition in pharmacology: From theoretical knowledge of medicines to practice-oriented approach. Do roleplays help? Int J Basic Clin Pharmacol 2016;5:1528-32. 